\title{
Influence Factors of the Formation of ODA in Ultralong Fatigue Life Regime
}

\begin{abstract}
J. Nagata $^{1}$ and Y. Murakami ${ }^{1}$
${ }^{1}$ Department of Mechanical Engineering Science, Kyushu University, 6-101, Hakozaki, Higashi-ku, Fukuoka, 812-8581, Japan

ABSTRACT: Recent studies have provided a warning that fatigue failure can occur in the life regime exceeding $N=10^{7}$ and at stresses lower than the conventional fatigue limit. In the present study, the mechanism of fatigue failure in extremely high cycle regime was studied on bearing steels, SAE 52100. Specimens having a longer fatigue life had a particular morphology beside the inclusion at fracture origin. The particular morphology looked optically dark when observed by an optical microscope and it was named the optically dark area, ODA. The ODA looks a rough area when observed by SEM and AFM. In order to investigate the growth of ODA with cycles, the fatigue tests of multi-step loadings were carried out and the formation of ODA was compared with those of the specimens tested under a constant amplitude loading. The condition for the critical size of ODA for the start of conventional fatigue crack growth mechanism was analysed by fracture mechanics. The critical stress intensity factor range $\Delta K_{O D A}$ can be correlated with the threshold stress intensity factor range $\Delta K_{\text {th }}$ for small cracks expressed by the $\sqrt{\text { area }}$ parameter model.
\end{abstract}

\section{INTRODUCTION}

Recent studies [1-3] have provided sufficient data on the elimination of the conventional fatigue limit defined by $N=10^{7}$. Murakami et al [4-6] pointed out the presence of a particular morphology, i.e. an optically dark area (ODA) beside the inclusion from which ultralong fatigue fracture of hard steels originated. They also suggested that the formation of an ODA was presumed to be influenced by hydrogen trapped by inclusions. It was revealed that ODA size increases with increase in fatigue life $N_{\mathrm{f}}$. However, it is hard to measure undestructively the growth rate of ODA in unbroken specimens.

In the present study, in order to investigate the growth behaviour of ODA, step loading tension-compression fatigue tests were carried out with a bearing steel SAE52100. After investigating the fracture surface, the formation of ODA at a certain cycles was measured and compared with those of the specimens failed under constant amplitude loading. 


\section{TEST SPECIMENS AND EXPERIMENTAL METHOD}

A bearing steel, SAE52100 was used. Table 1 shows the chemical composition. In order to investigate the influence of the chemical composition of inclusions on the formation of ODA, materials containing more $\mathrm{Ti}, \mathrm{S}$, and $\mathrm{O}$ than a standard level were prepared. Specimens with a standard chemical composition (O:8ppm, Ti:0.001\%, S:0.002\%) were termed Specimen NN. Specimens containing a high level of O(15ppm) were termed Specimen NO. Specimens containing a high level of Ti(0.020\%) were termed Specimen NT. Specimens containing a high level of $\mathrm{S}(0.020 \%)$ were termed Specimen NS. These specimens were quenched at $840{ }^{\circ} \mathrm{C}$ and tempered at $180^{\circ} \mathrm{C}$. The specimens were polished with emery paper \#2000. Figure 1 shows the dimensions and shape of the tension compression fatigue specimen. The tension-compression tests were carried out with $R$ ratio $=-1$ and frequency $20 \sim 50 \mathrm{~Hz}$.

\section{EXPERIMENTAL RESULTS AND DISCUSSION}

\section{Surface Residual Stress and Hardness Distribution}

Compressive residual stress of approximately $500 \mathrm{MPa}$ was present on the specimen surface. However, it was confirmed that the residual stress disappeared by electropolishing the surface layer approximately a few 10 $\mu \mathrm{m}$. Figure 2 shows the $H V$ hardness distribution on the cross section of a specimen NN measured along all four radial directions. The $H V$ hardness distribution in Specimen NN, NT, NO and NS were almost same.

Table 1 Chemical composition of SAE52100

\begin{tabular}{|c|c|c|c|c|c|c|c|c|}
\hline Specimen & $\mathrm{C}$ & $\mathrm{Si}$ & $\mathrm{Mn}$ & $\mathrm{P}$ & $\mathrm{S}$ & $\mathrm{Cr}$ & $\mathrm{Ti}$ & $\mathrm{O}$ \\
\hline $\mathrm{NN}[6]$ & 0.97 & 0.18 & 0.27 & 0.016 & 0.007 & 1.33 & 0.001 & 8 \\
\hline NS & 0.98 & 0.26 & 0.40 & 0.010 & 0.020 & 1.40 & 0.001 & 9 \\
\hline NO & 0.98 & 0.25 & 0.39 & 0.010 & 0.003 & 1.40 & 0.001 & 15 \\
\hline NT & 0.99 & 0.26 & 0.39 & 0.010 & 0.002 & 1.40 & 0.020 & 8 \\
\hline
\end{tabular}

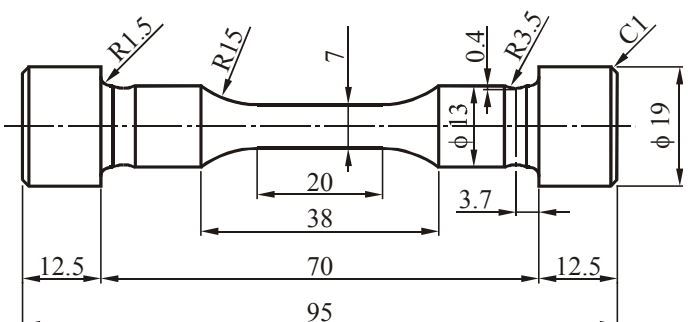

Figure 1 Tension-compression fatigue specimen (mm)

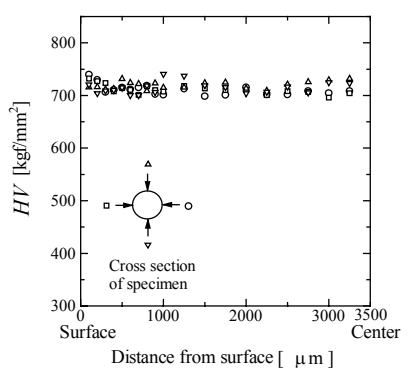

Figure 2 Hardness distribution at specimen section (SAE52100). 


\section{Results of Tension-compression Fatigue Test}

Table 2 shows the results of the fatigue tests. All fracture origins were at internal inclusions and a fisheye fracture pattern was observed. Chemical composition of inclusion was identified by means of X-ray analysis. Inclusions at fracture origin of Specimen NT, NO and NS were mostly Mgoxides or Al-oxides. Inclusions TiN and $\mathrm{MnS}$ whose density was increased by adding Ti and $\mathrm{S}$ were not observed at fracture origin. This is because the size of TiN and $\mathrm{MnS}$ is relatively smaller than $\mathrm{Mg}$-oxides and $\mathrm{Al}$-oxides. Thus, the size of inclusions is more crucial influencing factor in fatigue than numbers of inclusions.

Figure 3 shows the $S-N$ data. Measuring the size of the inclusions at fracture origin, the fatigue limit $\sigma_{\mathrm{w}}$ of each specimen was estimated by the $\sqrt{\text { area }}$ parameter model (Eq.(1)). The effective stress ratio $R$ was assumed to be $R=-1$, i.e., zero residual stress.

$$
\sigma_{\mathrm{w}}=1.56(H V+120) /(\sqrt{\text { area }})^{1 / 6}
$$

, where $\sigma_{\mathrm{w}}=$ fatigue limit (MPa), $H V=$ Vickers hardness number $\left(\mathrm{kgf} / \mathrm{mm}^{2}\right)$

Table 2 Results of fatigue tests.

(a) Standard constant amplitude tests * Specimen classification

\begin{tabular}{|c|c|c|c|c|}
\hline$*$ & $\sigma(\mathrm{MPa})$ & $N_{\mathrm{f}}$ & origin & $\sqrt{\text { area }}(\mu \mathrm{m})$ \\
\hline \hline NT & 711 & $2.57 \times 10^{7}$ & $\mathrm{Al} . \mathrm{Mg}$ & 39.9 \\
\hline NT & 721 & $2.77 \times 10^{7}$ & $\mathrm{Al}$ & 34.3 \\
\hline NO & 788 & $5.17 \times 10^{7}$ & $\mathrm{Mg}$ & 24.4 \\
\hline NO & 844 & $1.28 \times 10^{7}$ & $\mathrm{Al}$ & 19.9 \\
\hline NO & 879 & $9.15 \times 10^{6}$ & $\mathrm{Al}$ & 23.0 \\
\hline NO & 915 & $6.85 \times 10^{6}$ & $\mathrm{Al}$ & 20.7 \\
\hline NS & 904 & $4.99 \times 10^{6}$ & $\mathrm{Al}$ & 28.0 \\
\hline
\end{tabular}

(b) Step loading tests

\begin{tabular}{|c|c|c|c|c|}
\hline & 677 & $1.00 \times 10^{7}$ & not broken & \\
NT1 & 717 & $\rightarrow 1.00 \times 10^{7}$ & $\begin{array}{c}\text { not broken } \\
\text { not broken } \\
\text { 756 }\end{array}$ & 29.9 \\
& 796 & $\rightarrow 3.00 \times 10^{7}$ & $\begin{array}{c}\text { Al } \\
\text { N.06 }\end{array}$ & \\
\hline NT2 & 713 & $1.00 \times 10^{6}$ & not broken & 4 \\
& 751 & $\rightarrow 3.96 \times 10^{6}$ & Al & 48.4 \\
\hline
\end{tabular}

(c) Ran out and tested again at higher stress level

\begin{tabular}{|c|c|c|c|c|}
\hline NT3 & 668 & $1.00 \times 10^{8}$ & not broken & 22.9 \\
& 982 & $\rightarrow 1.48 \times 10^{6}$ & $\mathrm{Al}$ & 2.9 \\
\hline NO4 & $\begin{array}{c}667 \\
\end{array}$ & $\begin{array}{c}2.00 \times 10^{8} \\
\rightarrow 6.07 \times 10^{6}\end{array}$ & $\begin{array}{c}\text { not broken } \\
\mathrm{Al}\end{array}$ & 20.4 \\
\hline
\end{tabular}

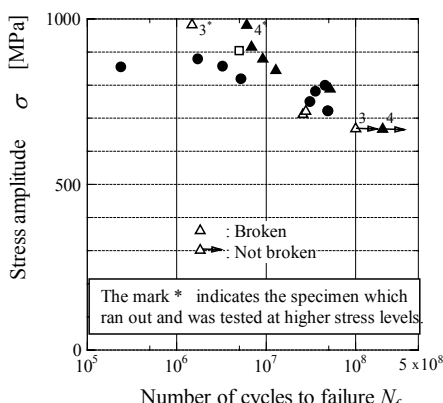

Number of cycles to failure $N_{f}$

•: Specimen NN (VQ): Heat treated in a vacuum followed by quenching and tempering [6]

$\Delta$ : Specimen NT: Quenched and tempered

: Specimen NO: Quenched and tempered

$\square$ : Specimen NS: Quenched and tempered

Fig. $3 \quad S$ - $N$ data ( SAE52100)

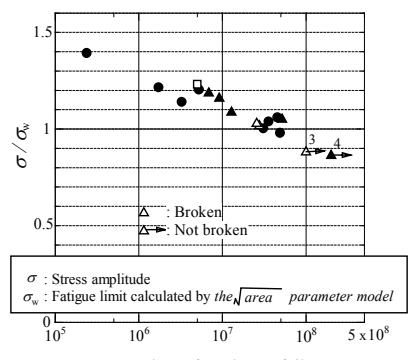

Number of cycles to failure $N_{f}$

-: Specimen NN(VQ): Heat treated in a vacuum followed by quenching and tempering [6]

$\Delta$ : Specimen NT: Quenched and tempered

$\boldsymbol{\Delta}$ : Specimen NO: Quenched and tempered

口: Specimen NS: Quenched and tempered

Fig. 4 Type 1 modified $S$ - $N$ data (SAE52100) 
and $\sqrt{\text { area }}=$ the square root of the projection area of an inclusion $(\mu \mathrm{m})$.

Figure 4 shows the modified $S-N$ data of type 1 where the vertical axis is the ratio between the applied stress and the fatigue limit estimated from Eq. (1), $\sigma / \sigma_{\mathrm{w}}$, vs. the cycles to failure $N_{\mathrm{f}}$. From this results, data presented indicates a trend that fatigue failure will occur even if the stress amplitude is below the estimated fatigue limit based on Eq. (1).

\section{Inclusions at Fracture Origins}

Figure 5 shows the optical micrographs near the fatigue fracture origin for Specimen NN. If the centre of the fish-eye mark is carefully observed using an optical microscope, a dark area can be found in most cases in the vicinity of the inclusion at fracture origin. This dark area has been termed ODA (Optically Dark Area) [4-6]. Figure 6 shows the relationship between ODA size and the cycles to failure $N_{\mathrm{f}}$. At longer fatigue lives the ODA size also increases [4-6].

\section{Fracture Mechanics Analysis of $O D A$}

Figure 7 shows the mechanism of growth of ODA for ultralong fatigue life regime [5]. ODA is presumed to be a result of cyclic crack growth under the influence of hydrogen trapped by an inclusion [4-6]. In other wards, ODA growth is not a pure fatigue mechanism but is the result of a synergistic effect combining both cyclic stress and hydrogen trapped by inclusions [6].
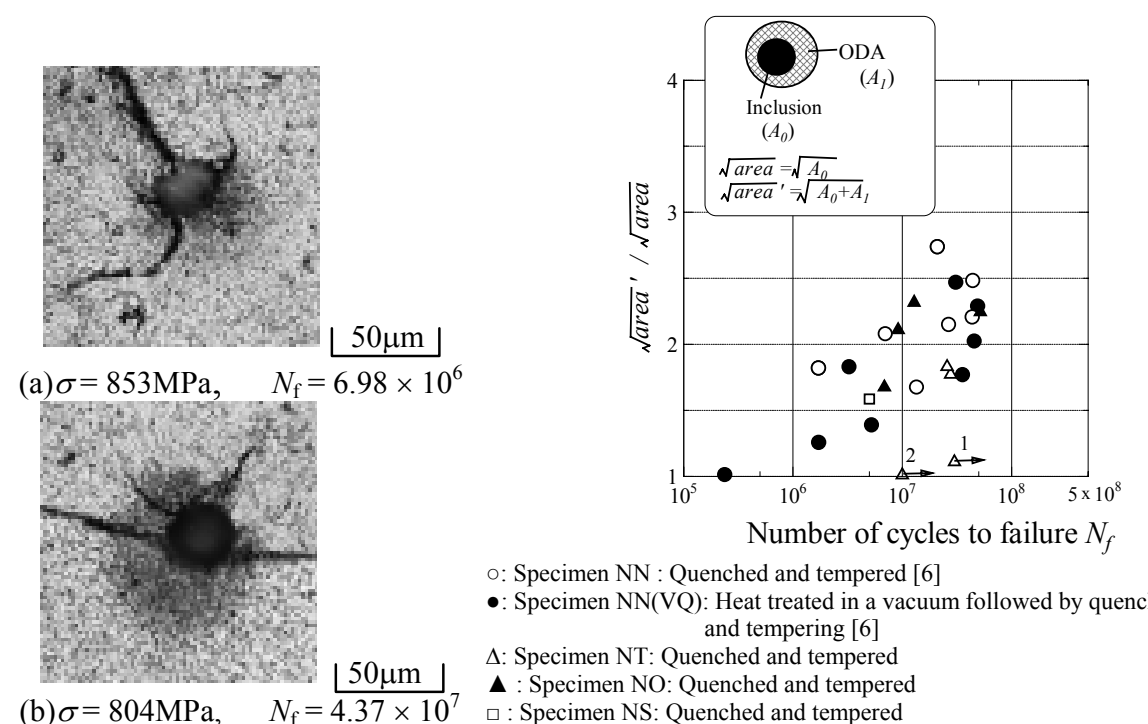

$\circ:$ Specimen NN : Quenched and tempered [6]

-: Specimen NN(VQ): Heat treated in a vacuum followed by quenching and tempering [6]

$\Delta:$ Specimen NT: Quenched and tempered

$\Delta$ : Specimen NT: Quenched and tempered

$\square:$ Specimen NS: Quenched and tempered

$\Delta 1$ : Growth of ODA until the third step of step loading tests.

Fig. 5 Fatigue fracture origin and $\Delta 2$ : Growth of ODA in the first step of step loading tests. $(\sigma=720$ and $760 \mathrm{MPa})$ ODA of quenched and tempered specimens (Specimen NN)[6].

Fig.6 Relationship between the size of ODA and cycles to failure $N_{\mathrm{f}}$ 


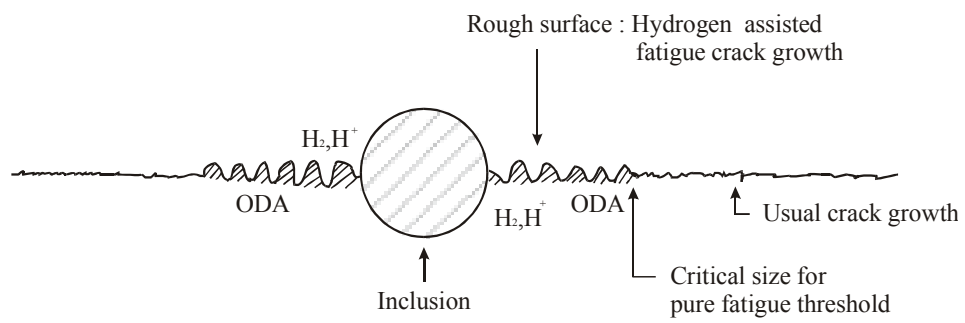

Fig. 7 Mechanism of growth of ODA for ultralong fatigue life regime[5]

Once the size of the ODA becomes large enough, the stress intensity exceeds the intrinsic threshold value and the fatigue crack propagates only due to cyclic loading without the assistance of hydrogen. It is well known that the threshold stress intensity factor ranges $\Delta K_{\text {th }}$ for small cracks are a function of crack size and lower than those for long cracks [8]. $\Delta K_{\text {th }}$ for small cracks and defects can be evaluated using the $\sqrt{\text { area }}$ parameter model by Murakami et al [7] as Eq. (2).

$$
\Delta K_{t h}=3.3 \times 10^{-3}(H V+120)(\sqrt{\text { area }})^{1 / 3}
$$

, where $\Delta K_{\mathrm{th}}: \mathrm{MPa} \cdot \sqrt{\mathrm{m}}, \sqrt{\text { area }}: \mu \mathrm{m}$, and $H V: \mathrm{kgf} / \mathrm{mm}^{2}$.

On the other hand, the values of $\Delta K_{\mathrm{ODA}}$ for the change of crack growth mechanism from inside ODA to outside ODA were evaluated by Eq. (3) [7] by assuming the size of defect to be $\sqrt{\text { area }}=($ inclusion + ODA $)$.

$$
\Delta K_{O D A}=0.5 \Delta \sigma \sqrt{\pi \sqrt{\text { area }}}
$$

, where $\Delta K_{\mathrm{ODA}}: \mathrm{MPa} \cdot \sqrt{\mathrm{m}}, \Delta \sigma: \mathrm{MPa}, \sqrt{\text { area }}: \mu \mathrm{m}$, and $H V: \mathrm{kgf} / \mathrm{mm}^{2}$. Figure 8 shows the relationship between $\Delta K_{\mathrm{ODA}}$ and $\sqrt{\text { area }}$. As the size of ODA $(\sqrt{\text { area }})$ decreases, $\Delta K_{\mathrm{ODA}}$ also decreases. The tendency is expressed as

$$
\Delta K_{O D A} \propto(\sqrt{\text { area }})^{1 / 3}
$$

Thus, the dependency of $\Delta K_{\mathrm{ODA}}$ on $\sqrt{\text { area }}$ is the same as the $\sqrt{\text { area }}$ parameter model [7]. Equation (4) indirectly supports the model of Fig. 7.

However, Sakai et al [9] reported that the values $\Delta K_{\mathrm{ODA}}$ evaluated by ODA size were constant. Therefore, their data were checked by Eq.(3) and compared with the data of the present study. The data $\square\left(N_{\mathrm{f}}>10^{6}\right)$ and $\mathbf{\square}\left(N_{\mathrm{f}}\right.$ $\left.<10^{6}\right)$ in Fig. 7 show $\Delta K_{\text {ODA }}$ calculated by Sakai's data[9]. The marks $\square\left(N_{\mathrm{f}}\right.$ $>10^{6}$ ) are dependent on ODA size and the tendency is similar to the present data. However, the tendency of $\square\left(N_{\mathrm{f}}<10^{6}\right)$ was different from other data. This is because ODA is hardly formed in $N_{\mathrm{f}}<10^{6}$ as indicated by the previous studies [6]. Thus, the data - satisfy in the following conditions. 


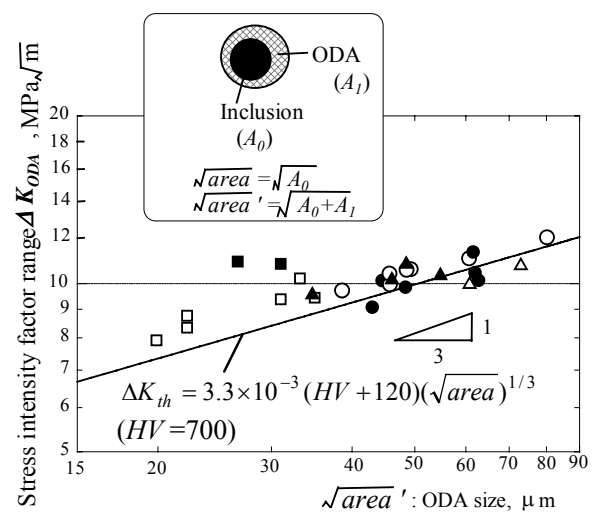

$\circ$ : Specimen NN(QT) : Quenched and tempered [6]

•: Specimen NN(VQ): Heat treated in a vacuum followed y quenching and tempering [6]

$\Delta$ : Specimen NT: Quenched and tempered

$\boldsymbol{\Delta}$ : Specimen NO: Quenched and tempered

$\square\left(N_{\mathrm{f}}>10^{6}\right), \boldsymbol{(}\left(N_{\mathrm{f}}<10^{6}\right)$ : Data by Sakai et al. [9]

Fig. 8 Relationship between $\sqrt{\text { area }}$ and $\Delta K_{O D A}$

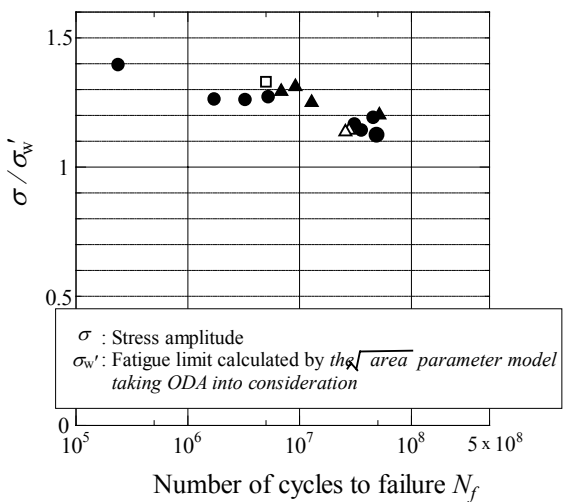

-: Specimen NN[6]: Heat treated in a vacuum followed by quenching and tempering .

$\Delta$ : Specimen NT: Quenched and tempered

$\boldsymbol{\Delta}$ : Specimen NO: Quenched and tempered

$\square:$ Specimen NS: Quenched and tempered

Fig. 9 Type 2 modified S-N data (SAE52100)

(1) The inclusion size at fracture origin is sufficiently larger than critical size of inclusion under the applied stress.

or,

(2) The applied stress is sufficiently higher than the fatigue limit in presence of the inclusion.

The values of $\Delta K_{\mathrm{ODA}}$ in Fig. 8 range from 7.92 to $12.1 \mathrm{MPa} \cdot \sqrt{\mathrm{m}}$ due to the difference of ODA size $(20-80 \mu \mathrm{m})$ and the values can not be regarded a constant values.

Figure 9 shows another modified $S-N$ diagram. The fatigue limit $\sigma_{W}{ }^{\prime}$ of each specimen was evaluated by the $\sqrt{\text { area }}$ parameter model adding the size of ODA to the original size of the inclusion. The value of $\sigma / \sigma_{W}{ }^{\prime}$ for fractured specimens exceeded 1.0 in all cases.

\section{Effect of Step Loading Fatigue Test on the Formation of ODA}

In order to investigate the mechanism of formation of ODA, step-loading fatigue tests were carried out. If a specimen ran out up to $N=1 \times 10^{7}$, the stress amplitude was raised by $40 \mathrm{MPa}$ and the fatigue test was continued until the specimen failed.

Table 3 shows the results of the tests for two specimens, NT1 and NT2. The test for specimen NT1 was started from the stress amplitude $\sigma=$ $680 \mathrm{MPa}$ up to $\sigma=800 \mathrm{MPa}$, with $N_{\mathrm{f}}=3.06 \times 10^{6}$ at $\sigma=800 \mathrm{MPa}$. The size of inclusion was $\sqrt{\text { area }}=29.9 \mu \mathrm{m}$ and the size of sum of ODA and inclusion 
Table 3 Results of the step loading fatigue tests. $\sqrt{\text { area }{ }^{850}}, \sqrt{\text { area }_{720}}$, etc are the sum of the ODA+ original inclusion size at each step. Arrows show the growth of ODA at each step loading.

\begin{tabular}{|c|c|c|c|c|c|c|c|}
\hline \multicolumn{6}{|c|}{ Specimen NT1 } & \multicolumn{2}{|c|}{ Specimen NT2 } \\
\hline 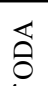 & $\begin{array}{c}\text { Stress } \\
\text { amplitude } \\
(\mathrm{MPa})\end{array}$ & 680 & 720 & 760 & 800 & 720 & 760 \\
\hline $\begin{array}{l}\text { 岁 } \\
\text { 索 }\end{array}$ & $\begin{array}{c}\text { Number of } \\
\text { cycles }\end{array}$ & $1 \times 10^{7}$ & $1 \times 10^{7}$ & $1 \times 10^{7}$ & $3.06 \times 10^{6}$ & $1 \times 10^{7}$ & $3.96 \times 10^{6}$ \\
\hline تี & $\begin{array}{c}\sqrt{\text { area }} \\
(\mu \mathrm{m})\end{array}$ & $\begin{array}{c}29.9 \\
+\end{array}$ & $\sqrt{\text { area }_{680}}$ & $\sqrt{\text { area }_{720}}$ & $\sqrt{\text { area }_{760}}$ & $\begin{array}{c}48.4 \\
\quad \\
\end{array}$ & $\sqrt{\operatorname{area}_{720}}$ \\
\hline & $\begin{array}{c}\sqrt{\text { area }^{\prime}} \\
(\mu \mathrm{m})\end{array}$ & $\sqrt{\text { area }_{680}}$ & $\sqrt{\text { area }_{720}}$ & $\sqrt{\operatorname{area}_{760}}$ & 47.9 & $\sqrt{\operatorname{area}_{720}}$ & $\begin{array}{l}71.7 \\
71.7\end{array}$ \\
\hline
\end{tabular}

was $\sqrt{\text { area }}=47.9 \mu \mathrm{m}$. The growth of ODA during the fatigue test at $\sigma=800 \mathrm{MPa}$ after the test of $\sigma=760 \mathrm{MPa}$ was estimated from Fig.6. The ratio of the $O D A+$ inclusion size at $\sigma=800 \mathrm{MPa}$ and $N_{f}=3.06 \times 10^{6}$ to the one at the end of the test at $\sigma=760 \mathrm{MPa}$ (the fourth step) is estimated (from the data of mark $\circ$ in Fig. 6 for $N_{\mathrm{f}}=3.06 \times 10^{6}$ )

$$
\sqrt{\text { area }_{800}} 1 / \sqrt{\text { area }_{760}} \cong 1.44
$$

, where $\sqrt{\text { area }_{760}}$ : the size of sum of ODA and inclusion size at the end of the fatigue test at $\sigma=760 \mathrm{MP}: \mu \mathrm{m} . \sqrt{\text { area }_{800}}$ ': the size of sum of ODA and inclusion size at $\sigma=800 \mathrm{MPa}$ and $N_{f}=3.06 \times 10^{6}: \mu \mathrm{m}$.

Since $\sqrt{\text { area }_{800}}=47.9 \mu \mathrm{m}$, we have $\sqrt{\text { area }_{760}}=33.3 \mu \mathrm{m}$ from Eq.(5). Thus, at the end of the test of $\sigma=760 \mathrm{MPa}$, it follows $\sqrt{\text { area }_{760}} / \sqrt{\text { area }}=33.3 / 29.9=1.11$

This value at the third step of the step loadings is plotted in Fig. 5 by the mark $\Delta 1$.

Table 3 also shows the test result for specimen NT2 which was tested from $720 \mathrm{MPa}$ to $760 \mathrm{MPa}$ and failed at $N_{\mathrm{f}}=3.96 \times 10^{6}$ at $\sigma=760 \mathrm{MPa}$. The size of inclusion was $\sqrt{\text { area }}=48.4 \mu \mathrm{m}$ and the sum of ODA and inclusion size was $\sqrt{\text { area }}=71.7 \mu \mathrm{m}$. The growth of ODA during the fatigue test at $\sigma=$ $760 \mathrm{MPa}$ after the test of $\sigma=720 \mathrm{MPa}$ was estimated from Fig. 6 . The ratio of the ODA inclusion size at $\sigma=760 \mathrm{MPa}$ and $N_{f}=3.96 \times 10^{6}$ to the one at the end of the test at $\sigma=720 \mathrm{MPa}$ (the second step) is estimated as

$$
\sqrt{\text { area }_{760}} 1 / \sqrt{\text { area }}=1.46
$$

Since $\sqrt{\text { area }_{760}}=71.7 \mu \mathrm{m}$, we have $\sqrt{\text { area }_{720}}=49.1 \mu \mathrm{m}$ from Eq.(3). Thus, at the end of the test of $\sigma=720 \mathrm{MPa}$, it follows

$$
\sqrt{\text { area }_{720}} / \sqrt{\text { area }}=49.1 / 48.4=1.01
$$


This value at the first step loading is plotted in Fig. 6 by the mark $\Delta 2$. The data $\Delta 1$ and $\Delta 2$ are the values in the earlier stage of step loading fatigue tests and are much smaller than the critical values shown by the mark $\Delta$.

\section{CONCLUSIONS}

To investigate growth of ODA, tension-compression fatigue tests of a step loadings were carried out with a bearing steel SAE52100. The Formation of ODA was compared with those of the specimens tested under constant amplitude loading.

(1) ODA size during the test of step loading was evaluated by using the growth curve of ODA under constant amplitude loading.

(2) $\Delta K_{\mathrm{ODA}}$ is dependent on ODA size and is not constant. As ODA size decreases, $\Delta K_{\mathrm{ODA}}$ also decreases. The dependency of $\Delta K_{\mathrm{ODA}}$ on ODA size is the same as the $\sqrt{\text { area }}$ parameter model.

(3) Fatigue design in ultralong fatigue life regime is possible with the combination of the master growth curve of ODA and the $\sqrt{\text { area }}$ parameter model.

\section{REFERENCES}

1. Naito, T., Ueda, H. and Kikuchi, M. (1983) Journal of Society of Material Science, Japan, 32-361, p.1162.

2. Abe, T. and Kanazawa, K. (1996) Journal of Society of Material Science, Japan, 45-1, p. 9.

3. Nakamura, T., Kaneko, M., Noguchi, T. and Jinbo, K. (1998) Trans. of the Japan Society of Mechanical Engineers, A, 64- 623, p. 1820.

4. Murakami, Y., Nomoto, T. and Ueda, T. (1999), Fatigue Fract. Engng. Mater. Struct., Blackwell Science Ltd., Vol. 22, p. 581.

5. Murakami, Y., Nomoto, T., Ueda, T., Murakami, Y. and Ohori, M.(1999) Journal of Society of Material Science, Japan, 48-10, p. 1112.

6. Murakami, Y. Yokoyama, N.N. and Takai, K. (2001) Journal of Society of Material Science, Japan, 50-10, p. 1068.

7. Murakami, Y. (1993) Metal Fatigue: Effects of Small Defects and Nonmetallic Inclusions, Yokendo Ltd., Tokyo.

8. Kitagawa, H and Takahashi, S. (1979) Trans. of the Japan Society of Mechanical Engineers, A, 45-339, p. 1289.

9. Sakai, T., Sato, Y. and Oguma, N. (2001) Trans. of the Japan Society of Mechanical Engineers, A, 67-664, p.1980. 